\title{
DESAIN $E$-MODUL BERBASIS KEMARITIMAN PADA MATAKULIAH KIMIA LINGKUNGAN DENGAN PENDEKATAN PROJECT BASED LEARNING
}

\section{E-MODULE DESIGN BASED ON DEMOCRACY IN ENVIRONMENTAL CHEMSITRY WITH PROJECT BASED LEARNING APPROACH}

\author{
Friska Septiani Silitonga*, Fitriah Khoirunnisa \\ Pendidikan Kimia, Fakultas Keguruan dan Ilmu Pendidikan, Universitas Maritim Raja Ali Haji \\ Jl. Politeknik Senggarang, Tanjungpinang, 29125, Indonesia \\ *e-mail korespondensi: friska.septiani89@umrah.ac.id
}

\begin{abstract}
Abstrak
Perkembangan teknologi informasi yang semakin pesatnya telah melingkupi setiap elemen bidang ilmu termasuk dalam bidang pendidikan. Salah satu pemanfaatan teknologi informasi dalam bidang pendidikan yaitu pembuatan media pembelajaran atau bahan ajar elektronik dan atau interaktif. Selain model, pendekatan, dan metode pembelajaran yang diperlukan dalam proses pembelajaran, bahan ajar dan media pembelajaran juga diperlukan agar meningkatkan minat dan motivasi mahasiswa dalam pembelajaran. Permasalahan yang dihadapi mahasiswa dalam pembelajaran kimia lingkungan yaitu belum tersedianya bahan ajar yang dapat digunakan mahasiswa serta belum mempunyai kemampuan analisis untuk menghubungkan antara ilmu kimia yang diperoleh dengan permasalahan lingkungan disekitar. Oleh sebab itu, dalam penelitian ini dibuat modul kimia lingkungan dengan memanfaatkan aplikasi Kvisoft Flipbook maker untuk membuat modul elektronik. Tujuan dari penelitian ini adalah membuat rancangan (desain) modul elektronik kimia lingkungan dengan pendekatan project based learning $(\mathrm{PjBL})$. Penelitian ini menggunakan metode deskriptif atau menggambarkan proses desain dari modul elektronik kimia lingkungan dengan pendekatan PjBL dengan menggunakan Kvisoft Flipbook Maker. Dalam desain modul elektronik ini menggunakan beberap fitur seperti corel draw untuk meningkatkan tampilan modul seperti cover dan desain kertas dengan menggunakan tema kemaritiman atau potensi lokal Provinsi Kepulauan Riau yaitu laut,dan gonggong, sedangkan untuk membuat modul elektronik digunakan dan Kvisoft Flipbook maker pro versi 4.0.
\end{abstract}

Kata kunci: kvisoft flipbook maker, modul elektronik, pendekatan project based learning

\begin{abstract}
The progress of information technology which was increasingly developed has encompassed every element of the field of science included of education. One of the used of information technology in the education field was the created of learning media or electronic and or interactive teaching materials. In addition to the models, approaches, and learning methods needed in the learning processed, teaching materials and learning media were also needed to increase students' interest and motivation in learning. The problems experienced by students in the study of environmental chemistry were the unavailability of teaching materials that can be used by students and did not have the analytical ability to connect the chemistry obtained with the surrounding environmental problems. Therefore, in this research was made an environmental chemistry module by utilizing the Kvisoft Flipbook maker application to make electronic module. The aimed of this research was to design electronic environmental chemistry modules with a project based learning approach $(\mathrm{PjBL})$. This research used descriptive methods or describes the design processed of the environmental chemistry electronic module with the PjBL approach used Kvisoft Flipbook Maker. In the design of this electronic module used features such as corel draw to improve the appearanced of modules such as paper cover and design using maritime themes or local potential of Riau Islands Province as the sea, and gonggong, while to make electronic modules used and Kvisoft Flipbook maker pro version 4.0.
\end{abstract}

Keywords: kvisoft flipbook maker, electrnic module, project based learning approach 


\section{PENDAHULUAN}

Selain model, metode, dan pendekatan yang mempengaruhi proses pembelajaran maka bahan ajar juga merupakan komponen penting dalam proses pembelajaran. Selain dapat digunakan di ruang belajar, bahan ajar juga dapat digunakan oleh mahasiswa untuk pengembangan diri diluar ruang pembelajaran. Bahan ajar merupakan seperangkat materi pelajaran yang mengacu pada kurikulum yang digunakan dalam rangka mencapai standar kompetensi dan kompetensi dasar yang telah ditentukan (Lestari,2013). Salah satu contoh bahan ajar yaitu modul pembelajaran.

Permasalahan yang selama ini dialami oleh mahasiswa selama pembelajaran kimia lingkungan yaitu (1) tidak tersedianya bahan ajar seperti modul, buku ajar, dan sebagainya (2) mahasiswa belum mampu menghubungkan konsep kimia dengan permasalahan lingkungan di sekitar seperti pencemaran air, tanah, dan udara, (3) kurangnya keterampilan mahasiswa dalam mengerjakan suatu proyek untuk analisis dan penyelesai masalah lingkungan.

Berdasarkan permasalahan ini, maka peneliti membuat rancangan modul ajar berbasis kemaritiman yang disesuaikan dengan kondisi dari Provinsi Kepulauan Riau yaitu daerah maritim dengan menggunakan pendekatan project based learning (PjBL). Berdasarkan perkembangan teknologi informasi, maka modul yang dirancang modul elektronik. Modul elektronik atau e-modul merupakan tampilan informasi dalam format buku yang disajikan secara elektronik dengan menggunakan hard disk, disket, CD, atau flash disk dan dapat dibaca dengan menggunakan komputer atau alat pembaca buku elektronik (Wijayanto \& Zuhri, 2014). Berdasarkan penelitian yang telah dilakukan oleh Suyoso \& Nurohman (2014) bahwa modul elektronik berbasis web dengan format mobile version dapat meningkatkan prestasi belajar siswa ditunjukkan dengan perolehan skor ternormalisasi sebesar 0,32.

Salah satu software yang dapat digunakan untuk pembuatan modul elektronik yaitu Kvisoft Flipbook maker. Keunggulan dari aplikasi ini adalah (1) mampu memberi efek flip, untuk membuka halaman modul; (2) pembuatan buku elektronik dengan aplikasi ini sangat mudah; (3) modul elektronik yang dihasilkan tidak berupa buku saja, tapi dapat dilengkapi dengan gambar, (4) produk yang dihasilkan dapat dipublikasikan dalam bentuk SWF atau Flash, HTML untuk di publikasikan melalui website. Perangkat lunak ini dapat mengubah tampilan PDF yang biasa yang hanya berupa teks saja namun dapat membuat modul ajar menjadi lebih variatif dengan adanya gambar dan video (Priwantoro dkk., 2018) serta diharapkan mahasiswa dapat menjadi lebih tertarik untuk mempelajari kimia lingkungan.

Kimia Lingkungan merupakan salah satu matakuliah wajib pada program studi pendidikan kimia Universitas Maritim Raja Ali Haji. Matakuliah ini berfokus pada kajian kimia dalam lingkungan seperti ekosistem, pencemaran air, tanah, udara, bahan kimia berbahaya dan beracun di lingkungan serta sustainable chemistry. Oleh sebab itu, maka dalam pembelajaran ini mahasiswa dituntut untuk dapat menjelaskan fenomena-fenomena di lingkungan dengan konsep kimia. Maka perlu dibuat bahan ajar yang dapat meningkatkan kemampuan kognitif dan pemahaman mahasiswa terhadap fenomena di lingkungan dengan modul elektronik dengan pendekatan project based learning (PjBL).

Pendekatan PjBL merupakan suatu pendekatan yang dapat menuntun mahasiswa untuk dapat menilai suatu permasalahan, mendesain suatu proyek, hingga mengevaluasi proyek yang dihasilkan. Keunggulan dari pendekatan ini yaitu mahasiswa dilatih untuk memecahkan masalah sehari-hari khususnya pencemaran lingkungan melalu kerja individu dan atau kelompok (Sarah, dkk, 2017). Oleh sebab itu, peneliti merancang modul elektronik pada matakuliah kimia lingkungan dengan pendekatan PjBL.

\section{METODE PENELITIAN}

Metode yang digunakan dalam penelitian ini yaitu deskriptif untuk menggambarka langkah-langkah pembuatan modul ajar elektronik berbasis kemaritiman dengan pendekatan PjBL. Pembuatan modul elektronik ini dirancang dengan menggunakan software Kvisoft Flipbook Pro versi 4.0, Ms. Office Word untuk membuat isi teks modul, corel Draw dan Photoshop digunakan untuk membuat rancangan halaman sampul modul serta tema kertas yang digunakan untuk modul ajar. Adapun tema kertas yang digunakan menggunakan tema laut dan gonggong yang merupakan potensi dari Provinsi Kepulauan Riau. File yang diimport ke software kvisoft flipbook Pro dalam bentuk PDF.

Rancangan modul elektronik ini terdiri dari beberapa tahapan yaitu: (1) pembuatan isi teks modul elektronik yang terdiri dari silabus, kegiatan pembelajaran, proyek, serta latihanlatihan, (2) pembuatan story board dari modul 
ajar kimia lingkungan berbasis kemaritiman dengan pendekatan $\mathrm{PjBL}$, (3) rancangan halaman sampul depan, (4) rancangan tema kertas yang digunakan, (5) pemilihan tema untuk modul ajar elektronik, (6) mempublish modul ajar elektronik kimia lingkungan berbasis kemaritiman dengan pendekatan PjBL dengan menggunakan HTML.

\section{HASIL DAN PEMBAHASAN}

Adapun hasil yang diperoleh dari penelitian ini yaitu:

1. Modul ajar elektronik ini memuat beberapa kegiatan pembelajaran yaitu (a) hakikat kimia lingkungan, ekosistem, (b) siklus dan kualitas air, (c) pencemaran air, (d) pencemaran tanah, (e) pencemaran udara, (f) sustainable/green chemistry, (g) kimia bahan berbahaya dan beracun, (h) toksikologi lingkungan.

2. Pembuatan story board

Story board merupakan pedoman dalam menempatkan komponen-komponen yang terdapat dalam modul ajar elektronik matakuliah kimia lingkungan berbasis kemaritiman dengan pendekatan PjBL. Rancangan story board pada modul elektronik ini dapat dilihat pada Tabel 1 .

Tabel 1. Story board model elektronik berbasis kemaritiman matakuliah kimia lingkungan dengan pendekatan PjBL

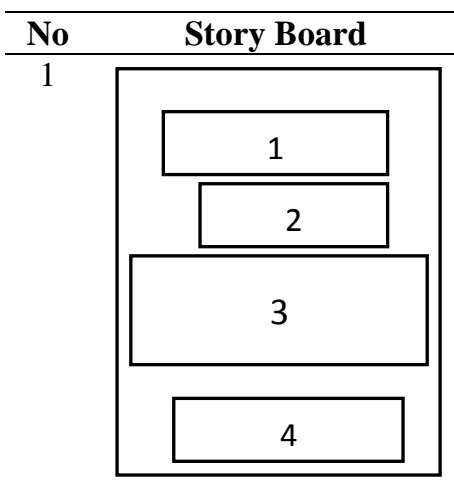

2

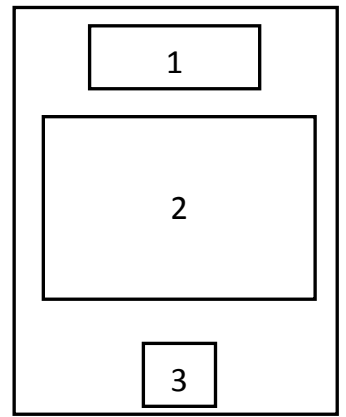

Kata Pengantar,

Daftar Isi, Daftar

Gambar, Daftar

Tabel

1. Nama/judul sub

2. Isi dari judul sub

3. Nomor Halaman

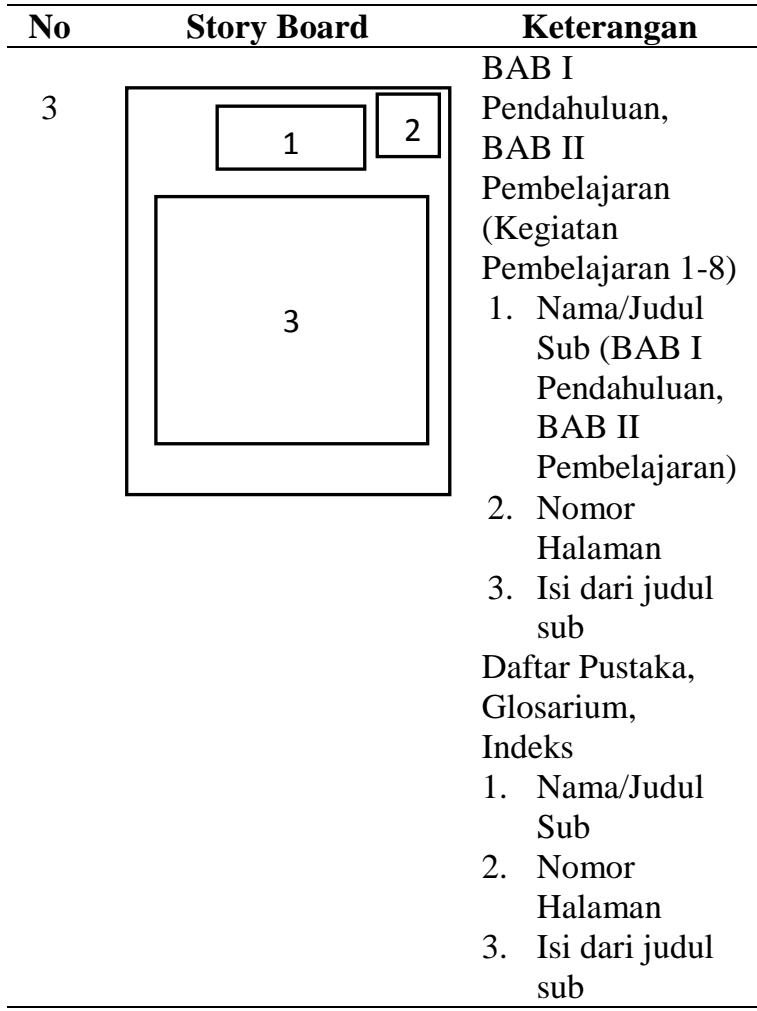

Dalam proses pembuatan story board ini dimaksudkan agar mempermudah penyusunan modul elektronik berbasis kemaritiman pada matakuliah kimia lingkungan dengan pendekatan PjBL. Story board ini dibuat sebelum modul dibuat dengan software kvisoft flipbook pro versi 4.0

3. Pembuatan halaman sampul depan modul dengan menggunakan corel Draw. Halaman sampul dibuat sesuai dengan fokus kimia lingkungan yaitu lingkungan air, tanah, dan udara. Pada halaman sampul juga tertulis nama pengarang dari modul ajar kimia lingkungan berbasis kemaritiman. Proses pembuatan halaman sampul dapat dilihat pada Gambar 1(a), sedangkan 1(b) halaman sampul depan yang telah jadi.

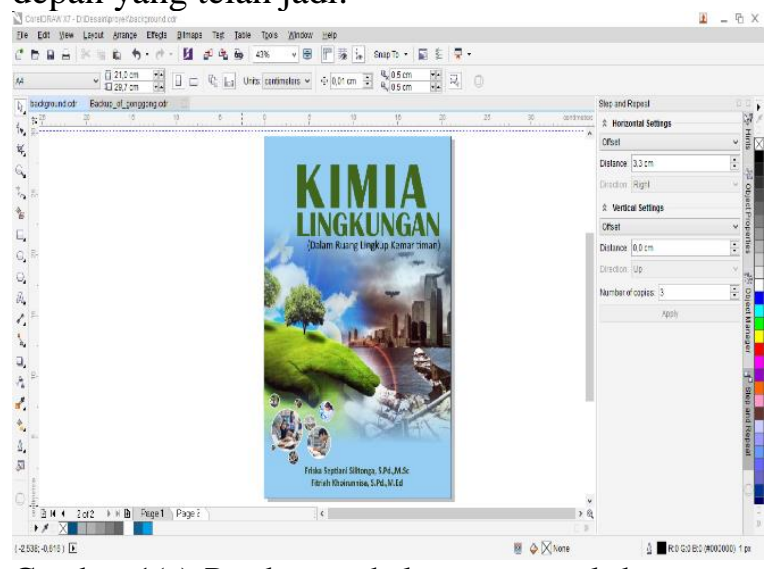

Gambar 1(a) Pembuatan halaman sampul dengan corel Draw 


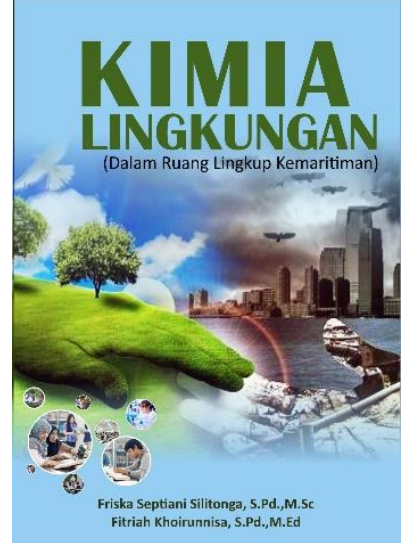

Gambar 1(b) Halaman sampul depan modul

4. Merancang tema dari kertas yang digunakan untuk modul ajar dengan menggunakan tema laut dan gonggong yang disesuaikan dengan potensi lokal yang dimiliki oleh Provinsi Kepulauan Riau. Dengan desain yang menarik tersebut dapat memberikan ketertarikan bagi pengguna modul sehingga ada keinginan untuk membuka dan belajar dengan modul tersebut. Desain tema kertas untuk modul elektronik dapa dilihat pada Gambar 2.

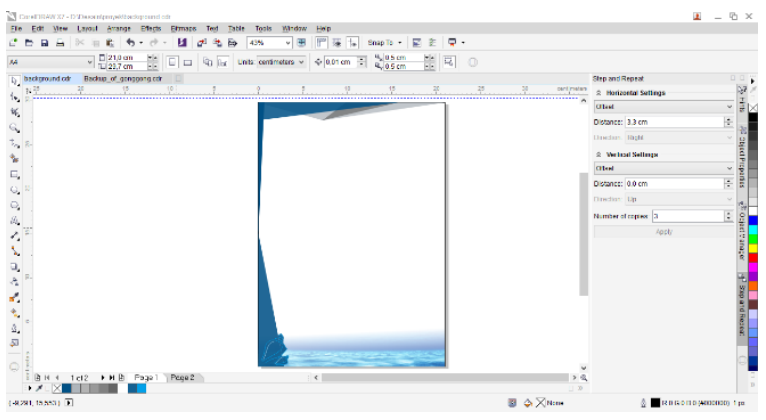

Gambar 2. Desain tema kertas pada modul elektronik

5. Pembuatan modul elektronik dengan menggunakan software Kvisoft Flipbook Pro 4.0

Sebelum membuat modul elektronik ini, maka file materi dari Ms Office word diubah terlebih dahulu ke bentuk PDF. Selanjutnya file PDF di import ke software Kvisoft Flipbook Pro 4.0. Tahapan dalam pembuatan modul elektronik dengan kvisoft flipbook maker dapat dilihat pada Gambar 3.

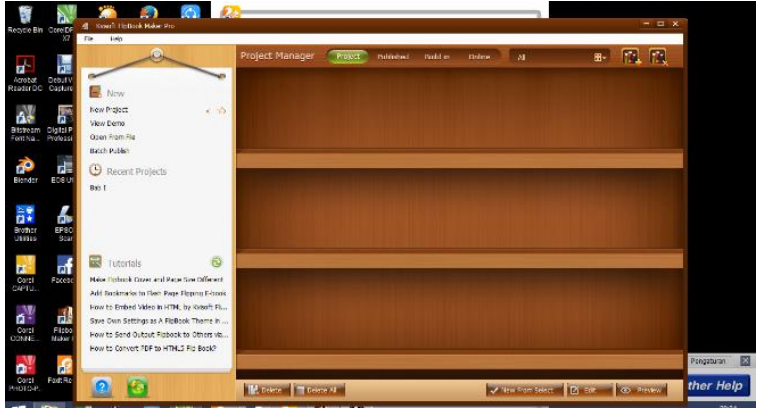

Gambar 3(a) Layar utama pada kvisoft flipbook maker

Pada awalnya pada menu "new project" untuk memasukkan file modul untuk dibuat kedalam kvisoft flipbook. Setelah memilih file yang akan di import maka tekan "open" dan akan muncul layar menu untuk mengatur ukuran dari filenya dan dapat dilihat pada Gambar 3(b) dan (c).

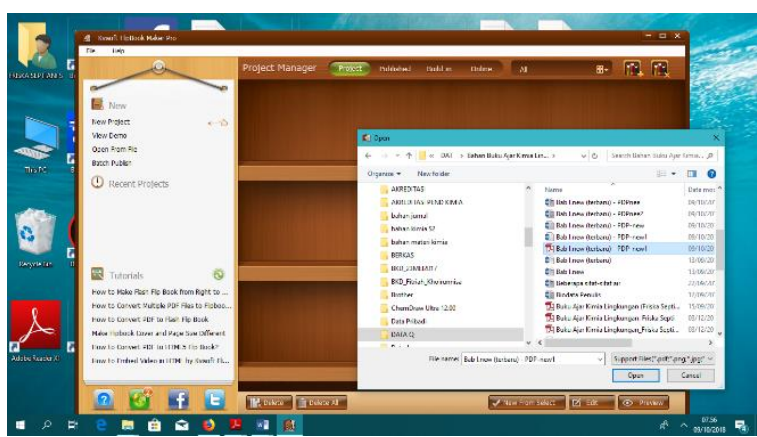

Gambar 3(b) Pemilihan file modul kimia lingkungan

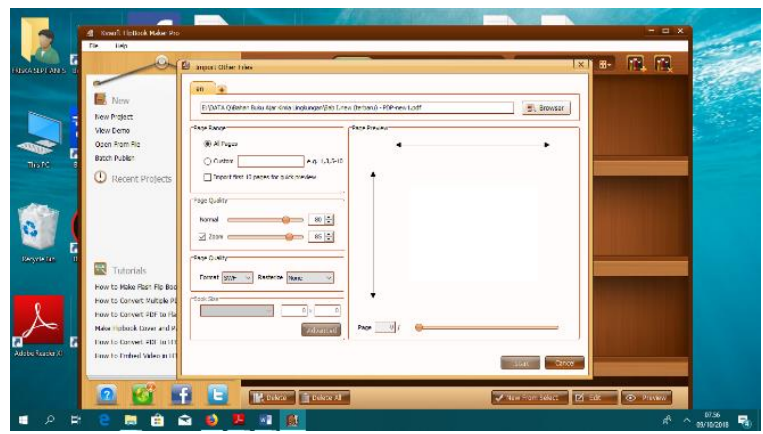

Gambar 3(c) Pengaturan tampilan modul kimia lingkungan

Setelah file halaman sampul dipilih dan diimport, maka selanjutnya dapat dilihat pada Gambar 3(d), kemudian peemilihan tema untuk tampilan modul elektronik dan kemudian di publish dengan menggunakan HTML 


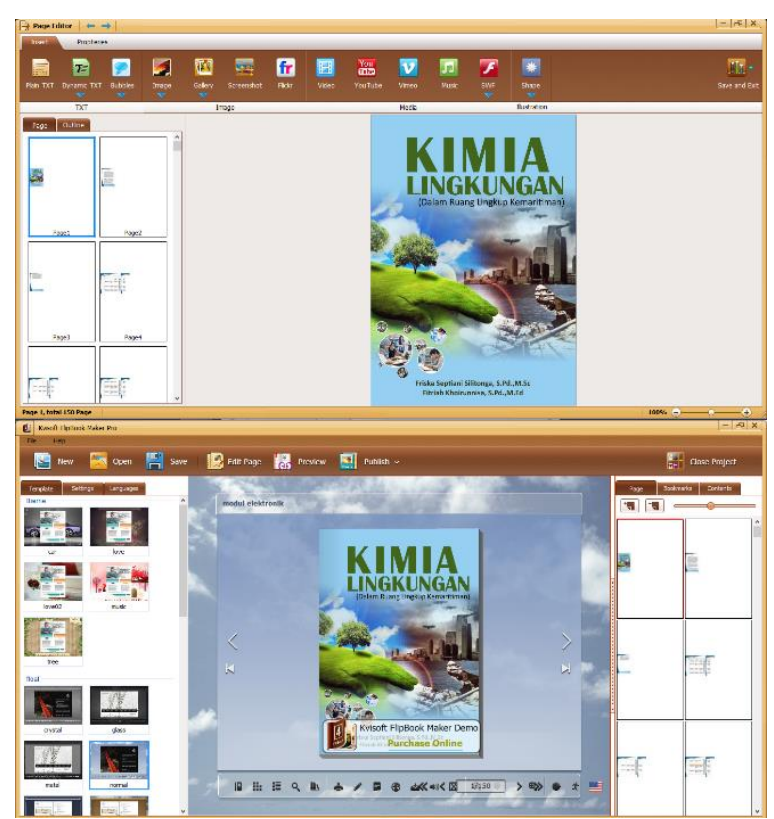

Gambar 3(d) Pembuatan halaman sampul dengan kvisoft flipbook

Setelah itu, hal yang sama juga dilakukan untuk pembuatan materi dalam modul elektronik berbasis kemartitiman dengan pendekatan $\mathrm{PjBL}$ dan ditunjukkan pada Gambar 3(e).

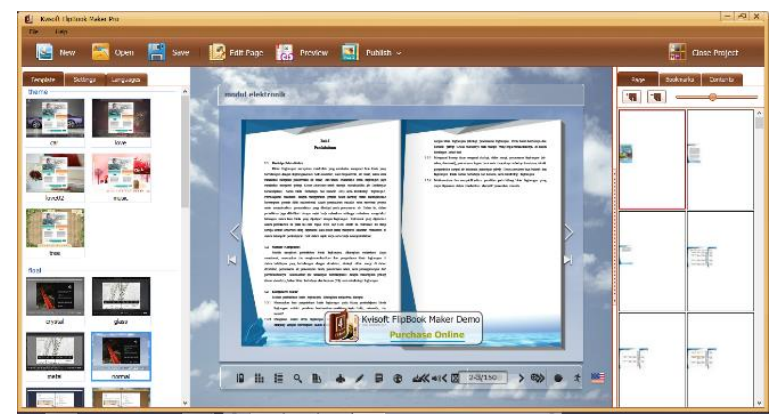

Gambar 3(e) Tampilan modul elektronik

Setelah selesai, maka hasil kerja di "publish" dengan menekan tombol "publish" dan memilih hasil kerja disimpan dengan format HTML, atau exe. Tampilannya dapat dilihat pada Gambar 3(f).

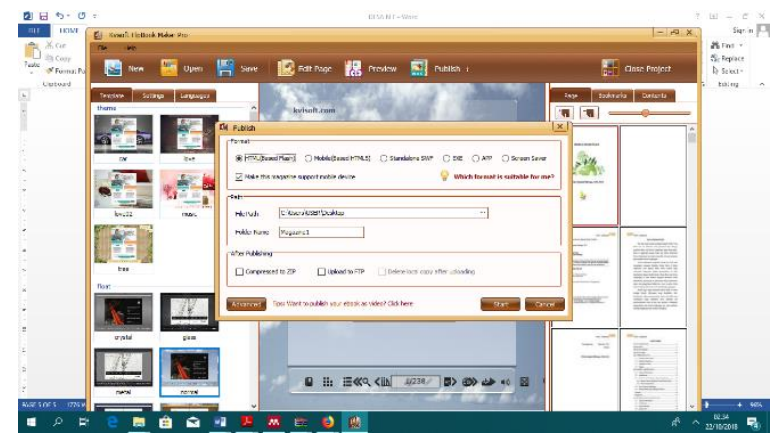

Gambar 3(f) Tampilan publish modul elektronik

\section{KESIMPULAN}

Berdasarkan hasil yang diperoleh bahwa modul elektronik berbasis kemaritiman pada matakuliah kimia lingkungan dengan memiliki desain yang baik dapat menarik dan meningkatkan motivasi dan minat belajar mahasiswa pada matakuliah kimia lingkungan. Pembuatan modul elektronik dengan menggunakan software kvisoft flipbook pro relatif lebih mudah untuk digunakan dalam proses pembuatan bahan ajar elektronik.

\section{UCAPAN TERIMAKASIH}

Peneliti mengucapkan terimakasih pada DRPM Kementerian Riset, Teknologi dan Pendidikan Tinggi melalui progran Hibah Penelitian Dosen Pemula 2018 yang telah mendanai penelitian ini serta UMRAH sebagai tempat terselenggaranya penelitian ini.

\section{DAFTAR RUJUKAN}

Lestari,I.. (2013). Pengembangan BahanAjar Berbasis Kompetensi (Sesuaidengan Kurikulum TingkatSatuan Pendidikan). Padang:Akademia Permata.134.

Priwantoro, S. W., Fahmi, S., Astuti, D., (2018). Analisis Kebutuhan Pengembangan Multimedia Berbasis Kvisoft Dipadukan dengan Geogebra pada Matakuliah Program Linear. AdMathEdu, 8(1). 49-57.

Sarah, R., Iskandar, F., \& Raditya, A. (2017). Pengembangan Bahan Ajar Project- Based Learning Berbantuan Scratch, disajikan dalam Seminar Nasional Matematika dan Aplikasinya pada 2017 di Universitas Airlangga..

Suyoso, \& Nurohman, S. (2014). Developing web-based electronics modules as physics learning media. Jurnal Kependidikan, 44(1), 73-82.

Wijayanto, \& Saifuddin Zuhri, M. (2014). Pengembangan E-Modul Berbasis Flip Book Maker Dengan Model Project Based Learning Untuk Mengembangkan Kemampuan Pemecahan Masalah Matematika. Prosiding Mathematics and Sciences Forum, 625-628. 